\title{
An Investigation on Non-English Majors' Capacity for Autonomous English Learning in Vocational College of China-Take Quzhou University for Example*
}

\author{
LIN Ju-ye \\ Quzhou University, Quzhou, China
}

\begin{abstract}
The ultimate purpose of language teaching and learning is to learn how to communicate with people from other cultures effectively, how to become the owner of learning, as well as how to nurture an autonomous learner for lifelong learning. Meanwhile, mastering and manipulating learning strategies is one important determinate factor of autonomy learning. The research is intended to explore junior college students' capacity for autonomy learning in Quzhou University in China from the perspectives of cognitive strategies, meta-cognitive strategies, communicative strategies, and resource strategies respectively through questionnaires, interviews, and class observations. It is hopefully expected to find out the key to developing learner autonomy.

Keywords: autonomous learning, cognitive strategy, meta-cognitive strategy, communicative strategy, resource strategies
\end{abstract}

\section{Introduction}

Cultivating autonomous learning ability is the need of social development in this new era since we are confronted with a great number of the unprecedented challenges, such as the rapid development of science and technology, the swift career changes, and the fast speed and high frequency of knowledge update. It cannot be denied that, in order to have the competence in lifelong learning, learners have to learn to how to learn. Furthermore, how to learn is one of the most important factors contributing to autonomy learning. It, to some extent, depends on the efficiency of autonomous learning. Thus, cultivating the ability of autonomous learning has become a basic educational aim as well as the essence of teaching and learning in the education field. The research is intended to explore junior college students' capacity for autonomy learning in Quzhou University in China from the perspective of cognitive strategies, meta-cognitive strategies, communicative strategies, and resource strategies respectively through questionnaires, interviews, and class observations. It is hopefully expected to find out the key to developing learner autonomy.

Quzhou University is located in Quzhou City, Zhejiang Province, China. It is a comprehensive university with junior college students and undergraduate students. However, the subjects in the research are junior college students who are non-English majors in the university. That is to say, they are called non-English majors in vocational college. According to more-than-ten-year observation, the traditional College English

\footnotetext{
* Acknowledgements: The paper is supported and funded by Key Subject Construction Program in Quzhou University. LIN Ju-ye, lecturer, M.A., Foreign Language Department, Quzhou University, Quzhou, China.
} 
class in which teachers often explain texts and students spend lots of time making notes, memorizing, and practicing language points can almost be exaggerated to be "teaching by holding hands", which is also one of the most evident obstacles of cultivating learner autonomy. What is more, students always have a summative assessment at the end of each semester. The old traditional assessment mode should be replaced by an effective assessment system which is supposed to combine formative assessment with summative one in College English teaching and learning. Obviously, it is high time to renew teaching pattern and explore a new teaching mode to promote learner autonomy and further improve the learning efficiency.

\section{Literature Review}

As a matter of fact, autonomy learning has existed in China for thousands of years. Confucius, the greatest of the ancient Chinese educators, should be the first person who came up with the essence of autonomy learning. Confucian doctrine includes numerous teaching sayings among which there is one that "Bu Fen Bu Qi; $\mathrm{Bu}$ Fei Bu Fa" means that "I will not enlighten my students until they have really tried hard but failed to understand. I will not instruct them until they have something to say but fail to make themselves understood". TAO Xing-zhi, one of the greatest educators during educational reform of the Republic of China, put forward autonomous learning in his paper titled "The Research of Students' Self-management" (DAI, 1991).

In Western countries, autonomy also has a history of decades. The origin of autonomy learning can date back to Europe in 1960s. According to Gremmo and Riley (1995), early interest in autonomy within the field of language education was aroused by the political turmoil in Europe in the late 1960s (cited by Benson, 2005, p. 7). Since Holec (1981, p. 1) began his report to the Council of Europe with a description of autonomy in the social and ideological context, the ideas of autonomy in learning have emerged. Apart from that, through systematic study and literature review, it has also been found that there are many different terms for autonomy learning, such as self-directed learning, self-access learning, learner autonomy, autonomous learning, etc. An increasing number of researchers and linguists suppose that these terms are similar to a large extent.

The definition of learner autonomy varies from person to person. Little (1991) argued "autonomy is a capacity - for detachment, critical reflection, decision-making, and independent action” (p. 4). Benson (2005, p. 47) defined autonomy as the capacity to take control of one's own learning. Autonomy is defined in the study that learners take all responsibilities for their own learning and make all decisions related to their learning tasks. Based on literature review on autonomous learning, the characteristics of autonomy learner are summarized as follows: Learners are ready to take charge of their own learning; learners study without the direct control of their teacher; learners decide their own learning goals and tasks; learners have their own learning styles and strategies; learners monitor the process of their own learning; learners decide the direction of their own learning; Learners evaluate the outcome of their own learning. Learners reflect on their learning to improve their learning efficiency.

\section{The Methodology of the Research}

On the basis of literature review and the characteristics of autonomy learner, two questionnaires were conducted in the research. One is English Class Questionnaire (ECQ); the other is Autonomy Learning Capacity Questionnaire (ALCQ). The subjects' responses to the questionnaires were processed through Microsoft Excel on the computer. The number of participants in this study was 154 second-year junior college students who are non-English majors with 83 males and 71 females in Quzhou University. Their age ranges 
from 19 to 21. They are from different majors in different departments in the university. The reason the paper chose the second-year non-English majors as subjects was that they had been accustomed to approaches to CET (College English Teaching) and had developed a more stable attitude towards College English learning. It is believed that more authentic data can be collected from this group. What is more, it is obvious that research data and result are more convincing by using questionnaires with in-depth interviews or other qualitative methods, such as class observations. Apart from that, a few interviews were conducted among some of the subjects and class observations were translated into words to reveal the students' general capacity of autonomy learning as well.

\section{Analysis and Discussion}

As is known to all, a teacher in class is supposed to be an organizer, stimulator, manager, instructor, facilitator, assistant, and so forth. Therefore, in the process of cultivating the capability of learner autonomy, the role of teachers cannot be replaced without any doubt. In the ECQ, when students are asked whether English teachers often teach them the approaches of language learning, nearly $60 \%$ of respondents indicate that their English teachers seldom mention or teach them learning strategies in class. Studies show that successful learners not only master some learning strategies but also are able to choose some effective strategies according to their learning tasks. Supposing teachers do not teach learners how to learn effectively, it is no longer possible for learners to improve learning efficiency, let alone develop their learning autonomy. When they are asked how English teachers influence their English study, it is found happily that most students (68\%) think English teachers have a positive influence on their English study. Meanwhile, to tell you the truth with regret, nearly one-third students reckon that their English teacher has no, even nearly negative impacts on their English study. If a teacher cannot guide learners to study better or more efficiently or strive for becoming ultimate autonomous learners, what is the use of the teacher? Learners are not inclined to become autonomy learners if teachers do not have advanced teaching frontier. Teachers should not be a knowledge transmitter but a learning strategy instructor as well as a knowledge facilitator. Moreover, the majority of respondents $(87 \%)$ express that few of English teachers use other learning materials to lessen their reading tiredness aside from the textbooks, let alone help them supplement or enrich their learning materials. A qualified language teacher ought to recommend some reference materials centered on teaching theme in accordance with learners' interest and level. This act can satisfy learners' various needs and stimulate their curiosity.

Autonomy Learning Capacity Questionnaire (ALCQ) is mainly divided into four parts including cognitive strategies, meta-cognitive strategies, communicative strategies, and resource strategies. The statistics from ALCQ show that the means range from the lowest 1.5390 to the highest 3.6623. The average of the mean scores is 2.5413. Because the ALCQ is a five-point scaled questionnaire, the figure "2.5413" shows that the capacity for autonomous learning of non-English majors in Quzhou University is comparatively weak, especially in learning strategies. The result coincides with the commonplace that the majority of English learners in China spend most of their time learning English in any old manner, yet the efficiency is not good enough. The reason can in part stem from the lack of effective learning strategies. To make the matter worse, English teachers rarely teach learners how to learn and just put more emphases on language points by instruction and explanation. The detailed statistics are concluded as follows: 


\section{Cognitive Strategies}

It is generally believed that cognitive strategies refer to the strategies by which learners gain knowledge and solve learning problems on their own. When the subjects are asked whether they know some knowledge on English learning strategies, nine students out of ten state that they do not acquire much. It is surprising that $11.7 \%$ of the students argue they do not have the slightest idea about it. It is also found that almost $59 \%$ are barely able to preview before lessons, review what they study in class timely, and do their assignments on time. It tells us that the junior college non-English majors not only are short of knowledge on learning strategies but have a passive attitude towards English learning. Half of the subjects claim that they would rather leave their puzzles alone than ask their teachers of questions in class. Just about $4.5 \%$ of students are willing to read some English learning materials out of class. Less than half of respondents can set up knowledge connections with the assistance of deduction and induction so as to solve learning problems. The statistics show that the junior college non-English majors in China are not very familiar with the cognitive strategy theory, not speak of its proper and flexible application. In an effort to pick up some basic approaches to English learning, teachers are expected to offer learners more interesting English materials according to students' needs and interests and introduce some more specific learning strategies on purpose. For one thing, the teaching way can arouse their interests in learning English; for another, it can lay a solid foundation on their learning autonomy.

\section{Meta-cognitive Strategies}

Meta-cognitive strategies refer to all the strategies that are used to plan, monitor, and adjust the learning process by learners. The average score of meta-cognitive strategies from ALCQ is 2.6326, which manifests that the capability of junior non-English majors in employing meta-cognitive strategies is unsatisfactory. According to the statistics, $54.5 \%$ of subjects learn English so aimlessly that they have no learning plans or goals. Only $9 \%$ of students will adjust their mood to work on learning questions when they feel bored. Nearly three quarters of subjects seldom reflect on their learning approaches and assess their learning efficiency. Almost none of them write journals in English. A number of students do not have a strong awareness of monitoring the process of their learning. It is found from class observation as well as interviews that the majority of students will panic or look up in the dictionary immediately while coming across new words or complex sentences. Therefore, numbers of non-English majors have no concrete and specific learning goal and are unable to monitor learning process effectively. Teachers are supposed to encourage students to keep calm and be confident in comprehending learning materials by a variety of ways, such as guessing meanings from context or word-formation, looking for the same connotation cited by antonyms or synonyms, and the rest.

\section{Communicative Strategies}

Communicative strategies mean all the strategies that students use to seize more opportunities for communication improvements. It is estimated that only a quarter of students take advantage of all kinds of opportunities to communicate with their peers in or out of class. Few students are ready to practice English at English Corner, let alone take their own initiative to talk with other students in English. The vast majority of the students are too shy to open the mouth, even when they need speak English. Different reasons should be taken into consideration to account for the phenomenon. For one thing, Chinese people are pretty modest and humble; for another, they are afraid of making mistakes and losing their faces. In order to avoid the embarrassment, they would just as soon keep quiet listening attentively to others speak. From the perspective of psychology, teachers are encouraged to ask students to convey their comment and reflection boldly in class, to 
make notes on their opinions, to write journals related, and even to retell what they have learned so as to have a deeper understanding and reach the point of learning autonomy.

\section{Resource Strategies}

Resource strategies refer to those strategies of resource selection in place that learners use to study effectively. The average score of resource strategies from ALCQ is 2.9656, which indicates that the capability of junior non-English majors in employing resource strategies is strong by comparison. It is found happily that most learners can enrich their learning resources through reference books, the Internet, or any other mass media. However, the absolute majority of the subjects are unwilling to take their initiative to seek help from English teachers. This is partly because students worry that their teacher will laugh at their questions or look down upon them. Faced with the dilemma, the first key factor to solve the problem is that teachers should instruct some right and effective approaches to problem-solving in class. Another key factor is that teachers are inclined to establish a close relationship with their students and build up harmonious and healthy teaching surroundings to improve their teaching-learning quality. In brief, it is essential to let learners know that whenever they encounter learning puzzles, they can not only ask for help from experts, teachers, classmates, and parents, but also get assistance from all kinds of references, mass media, and the Internet in time.

\section{Conclusion and Suggestions}

From the international perspective, since 1960s, autonomy has appeared in the field of language teaching. In effect, autonomous learning has a long history in China as well. Confucius, the Chinese greatest educator and thinker, is supposed to be the earliest person who stated that when the students are not ready, the teachers should hold back in their teaching. From what has been discussed above, the conclusion can be drawn that the capacity for autonomous learning of non-English majors in Quzhou University is comparatively weak, especially in learning strategies.

It is more reasonable that College English teachers in China are supposed to become autonomous practitioners and introduce strategy instructions into their language teaching to cultivate learner autonomy as the preparation for lifelong learners. It is commonly known that cultivating learner autonomy is a complicated process. Above all, cultivating the psychology of autonomy learning is the first step. In addition, the psychology of autonomy learning consists of learning motivation, learning interest, learning habits, and learning philosophy. Teachers are also expected to establish harmonious relationship with students and offer as many opportunities as possibly to learners for English practice. With a strong psychology of autonomy learning, teacher autonomy, positive classroom atmosphere, and a series of effective learning strategies, learners will be ready to take charge of their own learning as the owners. The roles of teacher and students will be shifted increasingly to promote learner autonomy better. Taking all these into account, it is high time to upgrade teaching opinions and cultivate learner autonomy.

The research is hopefully helpful to the exploratory reform of College English, for it displays some problems and weaknesses in autonomy learning of non-English majors in Quzhou University, China. It is apparent from the research that teachers should be autonomous practitioners and try to develop learner autonomy in language learning. Despite no deeper analysis of data, the discussion and result still have constructive references to language teachers. For some teaching suggestions mentioned in the paper are somewhat subjective and one-sided, its further research is hopefully expected to do in the future. 


\section{References}

Benson, P. (2005). Teaching and researching autonomy in language learning. Beijing: Foreign Language Teaching and Research Press.

DAI, Z. A. (1991). Tao Xingzhi's complete works (Vol. 1). Chengdu: Sichuan Education Press.

Gremmo, M. J., \& Riley, P. (1995). Autonomy, self-direction and self-access in language teaching and learning: The history of an idea. System, 23(2), 151-164.

Holec, H. (1981). Autonomy in foreign language learning (pp. 1-2). Oxford: Pergamon (First published 1979, Strasbourg: Council of Europe).

Little, D. (1991). Learner autonomy: Definitions, issues and problems (pp. 3-4). Dublin: Authentik. 